\title{
Rice bacterial blight pathogen Xanthomonas oryzae pv. oryzae produces multiple DSF-family signals in regulation of virulence factor production
}

\author{
Ya-Wen He*+1, Ji'en Wu+1, Jae-Soon Cha² and Lian-Hui Zhang*2
}

\begin{abstract}
Background: Xanthomonas oryzae pv. oryzae (Xoo) is the causal agent of rice bacterial blight disease. Xoo produces a range of virulence factors, including EPS, extracellular enzyme, iron-chelating siderophores, and type III-secretion dependent effectors, which are collectively essential for virulence. Genetic and genomics evidence suggest that Xoo might use the diffusible signal factor (DSF) type quorum sensing (QS) system to regulate the virulence factor production. However, little is known about the chemical structure of the DSF-like signal(s) produced by Xoo and the factors influencing the signal production.

Results: Xoo genome harbours an rpf cluster comprising rpfB, rpfF, rpfC and rpfG. The proteins encoded by these genes are highly homologous to their counterparts in X. campestris pv. campestris (XCC), suggesting that $X_{c c}$ and $X_{0 o}$ might use similar mechanisms for DSF biosynthesis and autoregulation. Consistent with in silico analysis, the rpfF mutant was DSFdeficient and the rpfC mutant produced about 25 times higher DSF-like activity than the wild type Xoo strain KACC 10331. From the supernatants of rpfC mutant, we purified three compounds showing strong DSF-like activity. Mass spectrometry and NMR analysis revealed that two of them were the previously characterized DSF and BDSF; the third one was a novel unsaturated fatty acid with 2 double bonds and was designated as CDSF in this study. Further analysis showed that all the three DSF-family signals were synthesized via the enzyme RpfF encoded by Xoo2868. DSF and BDSF at a final concentration of $3 \mu \mathrm{M}$ to the rpfF mutant could fully restore its extracellular xylanase activity and EPS production to the wild type level, but CDSF was less active than DSF and BDSF in induction of EPS and xylanase. DSF and CDSF shared a similar cell density-dependent production time course with the maximum production being detected at $42 \mathrm{~h}$ after inoculation, whereas the maximum production of BDSF was observed at $36 \mathrm{~h}$ after inoculation. When grown in a rich medium such as YEB, LB, PSA, and NYG, Xoo produced all the three signals with the majority being DSF. Whereas in nutritionally poor XOLN medium Xoo only produced BDSF and DSF but the majority was BDSF.

Conclusions: This study demonstrates that $X_{O O}$ and $X \subset C$ share the conserved mechanisms for DSF biosynthesis and autoregulation. Xoo produces DSF, BDSF and CDSF signals in rich media and CDSF is a novel signal in DSF-family with two double bonds. All the three DSF-family signals promote EPS production and xylanase activity in XOo, but CDSF is less active than its analogues DSF and BDSF. The composition and ratio of the three DSF-family signals produced by Xoo are influenced by the composition of culture media.
\end{abstract}

\section{Background}

The quorum sensing (QS) mechanism allows bacteria to sense their population density and synchronize individual activity into cooperative community behaviour [1-3],

*Correspondence: yawen@imcb.a-star.edu.sg, lianhui@imcb.a-star.edu.sg

1 Institute of Molecular and Cell Biology, 61 Biopolis Drive, 138673, Singapore

2 Department of Plant Medicine, Chungbuk National University, Cheongju 361-

763 , Korea

+ Contributed equally

Full list of author information is available at the end of the article which appears to provide bacterial pathogens an obvious competitive advantage over their hosts in pathogen-host interaction. In Gram-negative bacteria, in addition to the well-characterized AHL-type QS signals and AI-2, DSFfamily signals have recently been reported in a range of plant and human bacterial pathogens, including Xanthomonas campestris pv. campestris (Xcc), Xyllela fastidiosa, Stenotrophomonas maltophilia, and Burkholderia cenocepacia [4-9]. In Xcc, DSF has been characterized as 
cis-11-methyl-2-dodecenoic acid [5]. The putative enoylCoA hydratase RpfF is a key enzyme for DSF biosynthesis $[4,10]$. The DSF signalling system comprises several key regulatory proteins and a second messenger cyclic-diGMP (c-di-GMP). Among them, the RpfC/RpfG twocomponent system is involved in sensing and transduction of DSF signal through a conserved phosphorelay mechanism [10-12]; RpfG functions in turnover of the second messenger c-di-GMP and Clp is a novel c-diGMP receptor [12,13], which regulates the expression of DSF-dependent genes directly or indirectly via two downstream transcription factors Zur and FhrR [14]. In Xylella fastinosa, the structure of the DSF-like signal was characterized tentatively as 12-methyl-tetradecanoic acid by high-resolution gas chromatography-mass spectrometry (HRGC-EI-MS) analysis [6]. The DSF-like signal molecule (BDSF) from B. cenocepacia has been purified and characterized as cis-dodecenoic acid [9]. Moreover, DSF and several extracellular fatty acids have been identified from S. maltophilia by electrospray ionization mass spectrometry (ESI-MS) and gas chromatography and mass spectrometry (GC-MS analysis) [7]. Functional analysis of $r p f F$ or $r p f C$ mutants in different bacterial species suggests that the general role of the DSF-signaling system in the modulation of virulence seems to be conserved, but the regulatory mechanisms and DSF-dependent traits may differ among taxa [8,15-17].

Xanthomonas oryzae pv. oryzae (Xoo) is a causal agent of bacterial blight disease of rice [18]. Xoo enters either through wounds or hydathodes, multiplies in the epitheme and moves to the xylem vessels where active multiplication results in blight disease symptoms on rice leaves. Similar to Xcc, Xoo also produces a range of virulence factors, including EPS, extracellular enzyme, ironchelating siderophores, and the type III-secretion dependent effectors, which are collectively essential for virulence [19-23]. Null mutation of rpfC in Xoo wild type strain T3000 substantially affects the EPS synthesis and virulence [24]. The rpfF mutants of an Indian Xoo wild type isolate $\mathrm{BXO} 43$ are attenuated in virulence and defective in growth under low iron conditions [15]. More recently, a report showed that mutations in the core $r p f$ genes $r p f B, r p f F, r p f C$ and $r p f G$ reduced the EPS levels, xylanase activity, motility, and virulence of Xoo strain KACC10331 [25]. These findings suggest that DSF signalling system in Xoo is involved in the regulation of virulence factor production. However, little is known about the chemical structure of the DSF-family signals in Xoo and the factors influencing the signal production.

In this study, the comparative genomics analysis revealed that $X o o$ genome shares the key components of DSF biosynthesis and signalling with $X c c$. The DSF production assay of $r p f F, r p f C, r p f G$ mutants showed that $X o o$ uses a similar autoregulation mechanism as Xcc to control DSF biosynthesis. We further found that Xoo produces three DSF-family signals: DSF, BDSF and a novel signal with two double bonds, which was designated as CDSF. All the three DSF-family signals induce the EPS production and extracellular xylanase activity in the $r p f F$ mutant of Xoo with variable efficiencies. Moreover, we found that the production and the ratio of the DSF-family signals are affected by the culture medium composition.

\section{Results \\ Xoo uses the similar mechanism of Xcc in autoregulation of DSF biosynthesis}

In $X c c$, the $r p f$ cluster is involved in DSF biosynthesis, signal sensing and response. RpfF, a putative enoyl-CoA hydratase, is a key enzyme involved in DSF biosynthesis and mutation of rpfF abolishes DSF production [4]. RpfC negatively controls DSF biosynthesis by binding to RpfF at low cell density [10], and disruption of $r p f C$ results in a 16-fold higher DSF accumulation than the wild-type Xcc $[5,11]$. The genomes of three sequenced Xoo strains (KACC10331, MAFF311018 and PX099A) contain the $r p f$ cluster comprising $r p f B, r p f F, r p f G$ and $r p f C$, but not $r p f H$ [26-28]. These rpf homologous from Xcc and Xoo share more than $86 \%$ identify at the amino acids level (Fig. 1A), suggesting the conserved mechanism in DSF biosynthesis and in DSF signalling. To confirm this possibility, the $r p f F, r p f C$ and $r p f G$ mutants of Xoo strain KACC 10331, which were described previously [25], were assayed for DSF production. The results showed that the $r p f F$ mutant is DSF-deficient while the $r p f C$ mutant produced DSF signal around 25 times higher than its wild type parental strain did (Fig. 1B). The DSF production patterns of $r p f C$, $r p f F$ and $r p f G$ mutants of Xoo were very similar to those of $X c c[5,10,11]$, which indicates that, similar to XC1, Xoo also uses the RpfC-RpfF protein-protein interaction mechanism to autoregulate the biosynthesis of DSF-like signals.

\section{Xoo produces multiple DSF-family signals}

To identify the DSF-like signals produced by Xoo, we prepared the DSF extracts from the culture supernatants of the $r p f C$ mutant using a similar method as previously described [5] with two minor modifications. Firstly, we adjusted the $\mathrm{pH}$ of the supernatants of Xoo cell culture to 4.0 using concentrated hydrochloric acid before extraction by ethyl acetate. Secondly, formic acid was added at a final concentration of $0.1 \%$ to all the solvents for purification and high-performance liquid chromatography (HPLC) analysis. By using the DSF bioassay system described by Wang et al. [5], active fractions were collected and combined following flash column chromatography. Further separation using HPLC identified three active fractions with retention time at 15.7, 17.0, and 21.4 min, respectively, showing a maximum UV absorption at 


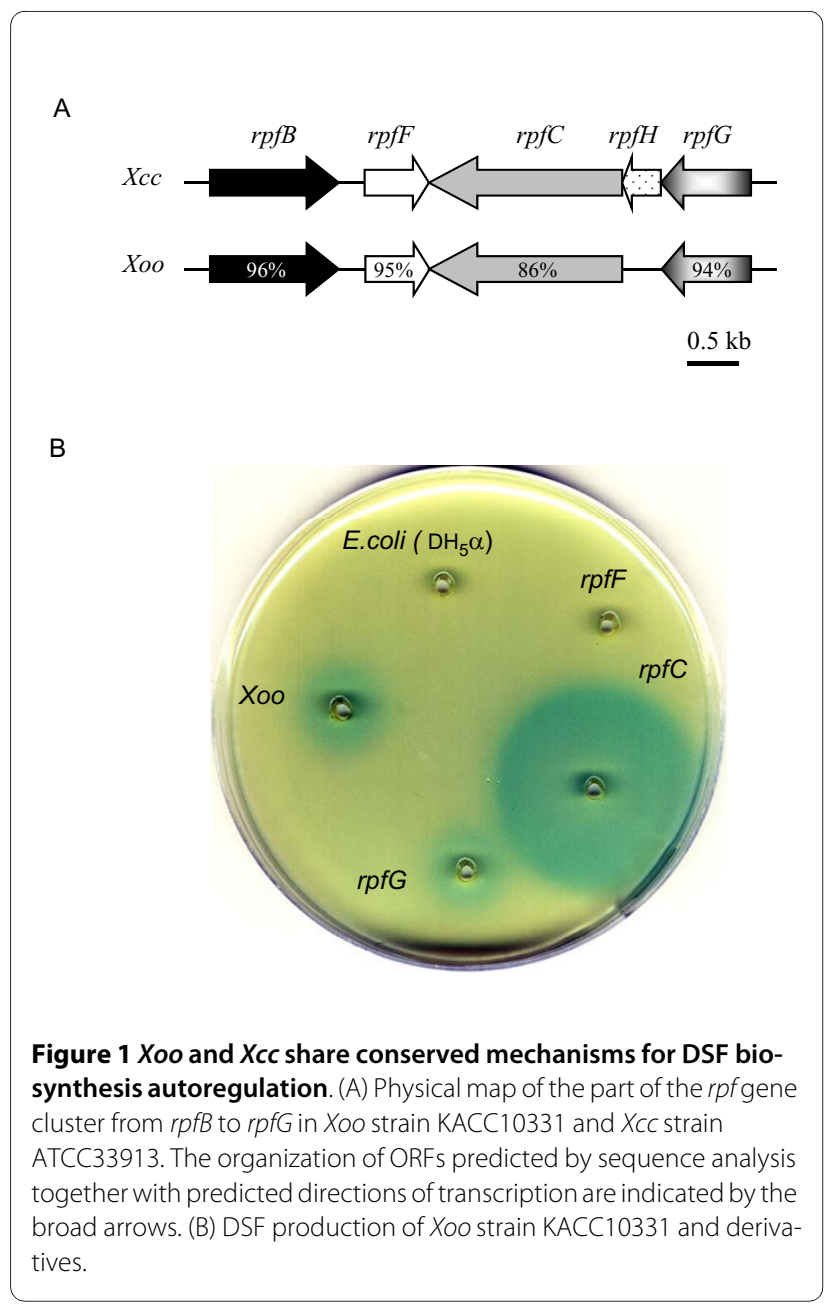

$212 \mathrm{~nm}$ and strong DSF activity in bioassay (Fig. 2A-B). High-resolution electrospray ionization mass spectrometry (ESI-MS) and NMR analysis showed that the compound in fraction A was cis-11-methyl-2-dodecenoic acid (DSF) (Additional file 1), which was originally reported in $X c c$ by Wang et al. [5]. The compound in fraction B showed the same NMR spectra and molecular weight as the BDSF signal from Burkholderia cenocepacia [9] (Additional file 2). The spectrometry data of fraction $C$ suggested a new member of the DSF-family signals (designated as CDSF) and its characterization was discussed in the following section.

\section{CDSF is a novel DSF-family signal}

High resolution MS analysis of CDSF showed a moleclar ion (M-H)- with a $m / z$ of 209.1555 , suggesting a molecular formula of $\mathrm{C}_{13} \mathrm{H}_{21} \mathrm{O}_{2}$ (209.1547) (Fig. 3A). ${ }^{1} \mathrm{H}$ NMR analysis revealed two pairs of methylenic protons. The coupling constants between the protons in each pair were lower than $12 \mathrm{~Hz}$ (Fig. 3B), suggesting the presence of two double bonds in cis configuration. The $\delta_{\mathrm{H}}$ of two methyl-

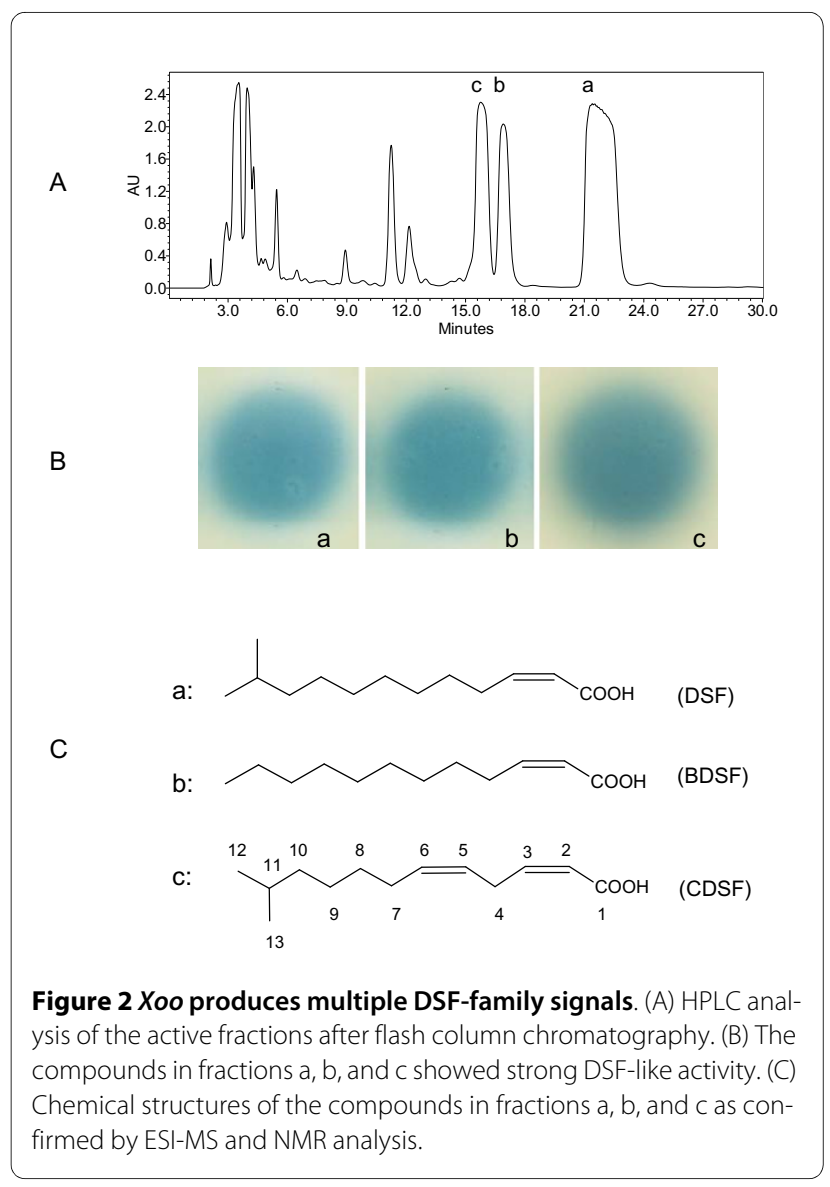

ene protons were at 3.45 , revealing a methylene carbon associated with two double bonds. The $\delta_{\mathrm{H}}$ of overlapped signals of two doublet methyl group were at 0.87 , indicating a DSF-like branched structure. ${ }^{13} \mathrm{C}$ NMR spectra analysis revealed that one double bond conjugated with the carbolic acid (Fig. 3C). Taken together, these data establish that CDSF is a novel unsaturated fatty acid, which is otherwise identical to DSF except the double bond between $\mathrm{C}_{5}$ and $\mathrm{C}_{6}$ (Fig. $2 \mathrm{C}$ ).

\section{DSF, BDSF and CDSF are synthesized via RpfF in Xoo}

Previous study showed that the signal DSF is synthesized via RpfF in Xcc [4]. Our results in Fig. 1B showed that deletion of $r p f F$ in Xoo resulted in loss of DSF-like activity, suggesting that DSF, BDSF and CDSF are all synthesized by RpfF in Xoo. For further verification, we compared the HPLC profiles of organic solvent extracts from Xoo wild type and its rpfF mutant. The results showed that the three fractions corresponding to DSF, BDSF and CDSF were detectable from the extracts of the Xoo wild type but not from the rpfF mutant (Additional file 3). 


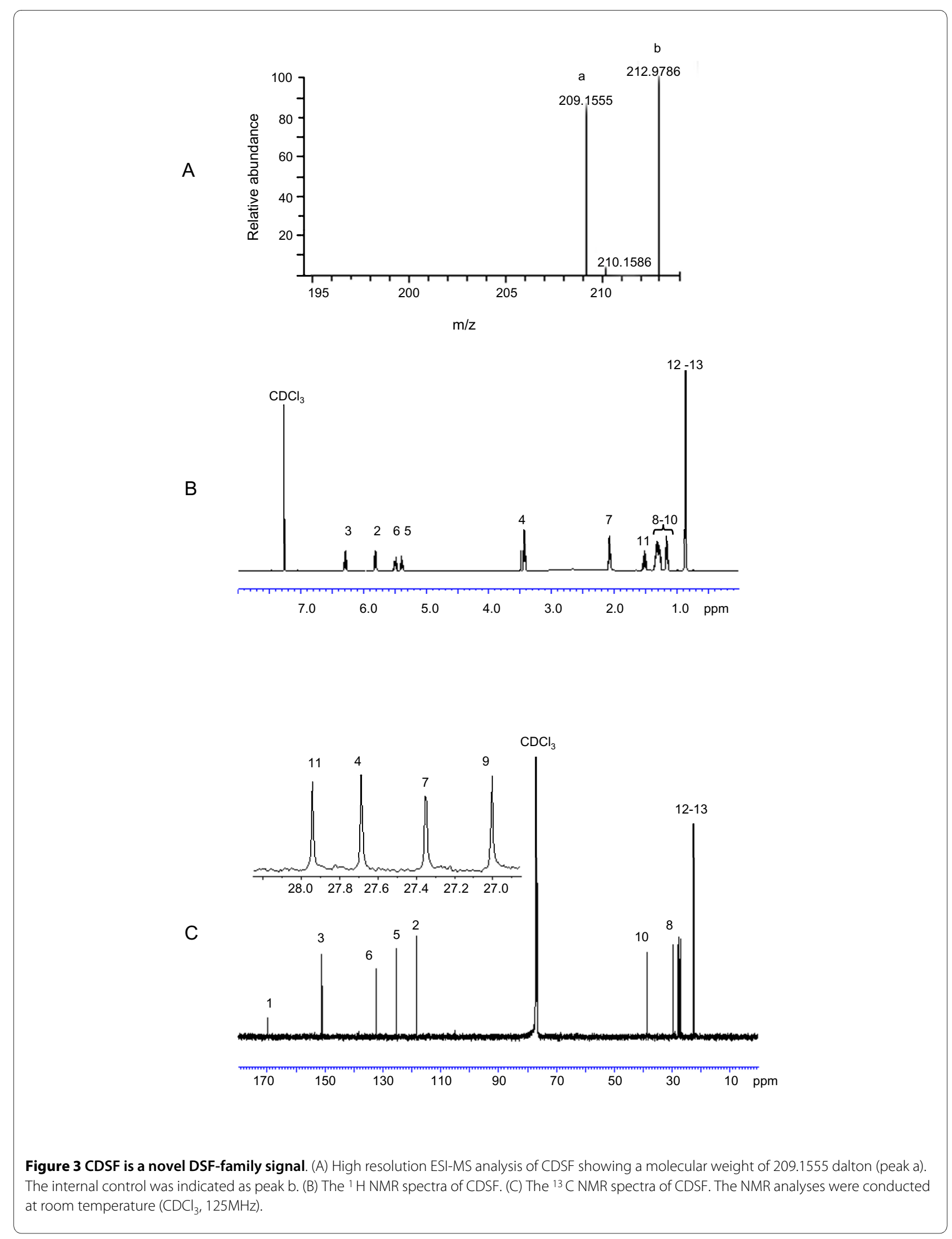


CDSF is a functional signal on induction of EPS production and extracellular xylanase activity

Previous findings in Xoo strain KACC10331 showed that mutation in $r p f F$ reduced the EPS production, xylanase activity, motility and virulence [25], suggesting the involvement of the DSF family signals in modulation of virulence factor production. In this study, the purified DSF, BDSF and CDSF were added separately to the rpfF mutant in a concentration range of 1 to $25 \mu \mathrm{M}$. After growth for $48 \mathrm{~h}$, the EPS production and the extracellular xylanase activity in the supernatants were determined. The results showed that $1 \mu \mathrm{M}$ of DSF or BDSF significantly stimulated EPS production and xylanase activity whereas $1 \mu \mathrm{M}$ of CDSF had no effect (Additional file 4). EPS production and extracellular xylanase activity of $r p f F$ mutant could be restored to wild-type level by addition of DSF or BDSF at a final concentration of $3 \mu \mathrm{M}$ (Additional file 4; Fig. 4). CDSF at the same concentration could only restore EPS production and xylanase activity to $77.0 \%$ and $68.5 \%$ of the wild type level, respectively (Fig.4).

\section{Three signals were differentially produced in Xoo}

The maximal DSF production in Xcc was found to be at the late stationary phase using a bioassay approach [5]. In this study, a more sensitive HPLC method was used to
A

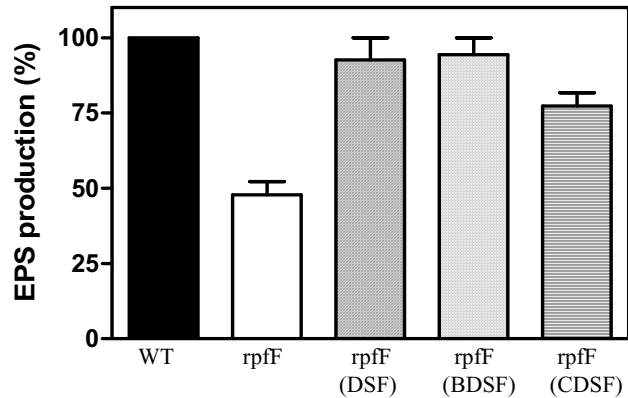

B

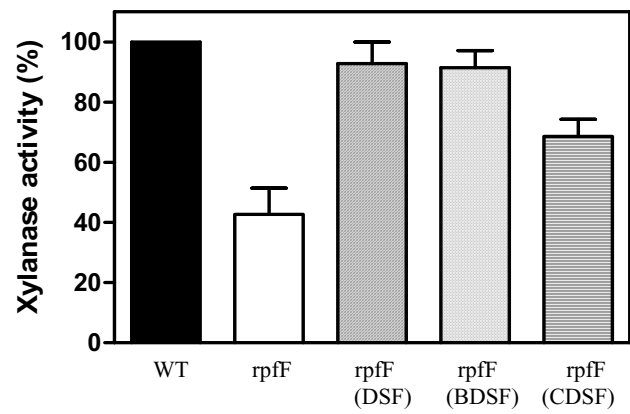

Figure 4 Effects of DSF, BDSF and CDSF on EPS production and extracellular xylanase activity of $r p f F$ mutant of Xoo strain KACC10331. (A) EPS production at $\mathrm{OD}_{600}=2.5$. (B) The xylanase activity in the supernatant of cell culture at $\mathrm{OD}_{600}=2.5$. DSF, BDSF and CDSF were separately added to $r p f F$ mutant at early growth stage at a final concentration of $3 \mu \mathrm{M}$. determine the production profiles of the DSF-family signals in Xoo. The bacterial strain was grown in the same medium for $48 \mathrm{~h}$ as described for Xcc [5], and the bacterial cell density and the levels of DSF, BDSF, and CDSF in the supernatants were monitored every 6 hours. The results showed that Xoo strains grew relatively slow during the first $30 \mathrm{~h}$ and then multiplied exponentially at about $36 \mathrm{~h}$ after inoculation (Fig. 5A). In agreement with this trend, the DSF level remained relatively low before 36 $h$ after inoculation and a substantial increase was observed at $42 \mathrm{~h}$ after inoculation (Fig. 5B). The CDSF shared a similar production pattern as DSF except that the CDSF level in the supernatants was around 10 times lower than that of DSF at $42 \mathrm{~h}$ after inoculation (Fig. $5 \mathrm{C}$ ). In contrast, the BDSF level in the supernatants increased

A

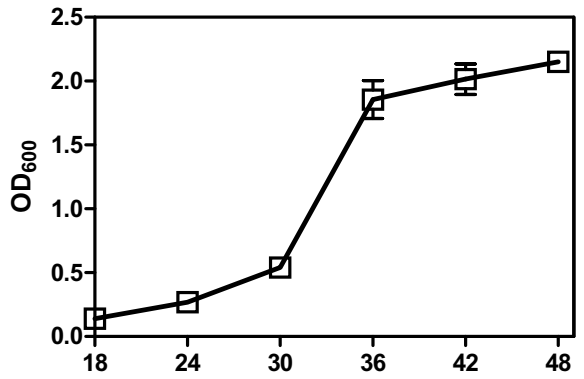

B
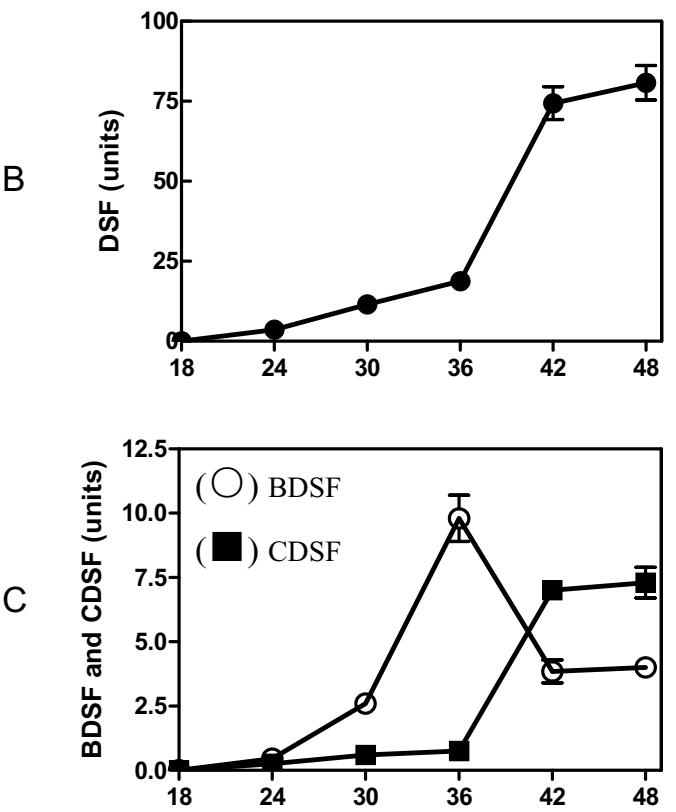

Figure 5 Time course of DSF, BDSF and CDSF production in Xoo during growth. (A) Time course of the bacterial growth in YEB medium. (B) Time course of DSF production. (C) Time course of BDSF and CDSF production. Units of DSF, BDSF and CDSF were determined by peak area in HPLC elute as indicated in Materials and Methods. 
stably from $18 \mathrm{~h}$ after inoculation and the maximal BDSF production occurred at $36 \mathrm{~h}$ after inoculation (Fig. 5C). A substantial decrease in BDSF production was observed 42 $\mathrm{h}$ after inoculation (Fig. 5C). At $36 \mathrm{~h}$ after inoculation, the BDSF level in the supernatants was around 2 times lower than that of DSF (Fig. 5C).

\section{Influence of culture media on signal production}

The differential signal production patterns shown in Fig. 5 suggest that substrate availability may be a factor in shaping the corresponding signal production profile. As the substrate availability could be influenced by nutritional composition and growth stages, we tested whether the signal production could be affected by culture media. To this end, the $r p f C$ mutant of Xoo strain was grown in 5 different culture media for $48 \mathrm{~h}$ to analyse the production of the 3 DSF-family signals. The results showed that the maximum cell density varied in different growth media. Among the 5 media tested, YEB medium supported the best bacterial growth $\left(\mathrm{OD}_{600}=2.5 \pm 0.2\right)$, followed by $\mathrm{LB}$ $\left(\mathrm{OD}_{600}=2.1 \pm 0.1\right)$, PSA $\left(\mathrm{OD}_{600}=2.1 \pm 0.1\right)$, NYG $\left(\mathrm{OD}_{600}\right.$ $=1.9 \pm 0.1)$ and $\mathrm{XOLN}\left(\mathrm{OD}_{600}=1.8 \pm 0.1\right)$. When grown in rich media such as YEB, LB, PSA, and NYG, Xoo strain produced all the 3 signals with the majority being DSF ranging from $56.7 \sim 83.9 \%$ (Fig. 6). However, when cultured in the nutritionally poor XOLN medium, Xoo produced only DSF and BDSF with $90 \%$ of them being BDSF (Fig. 6).

\section{Discussion}

In this study, based on the finding that DSF is a long chain fatty acid, we modified our previously developed method

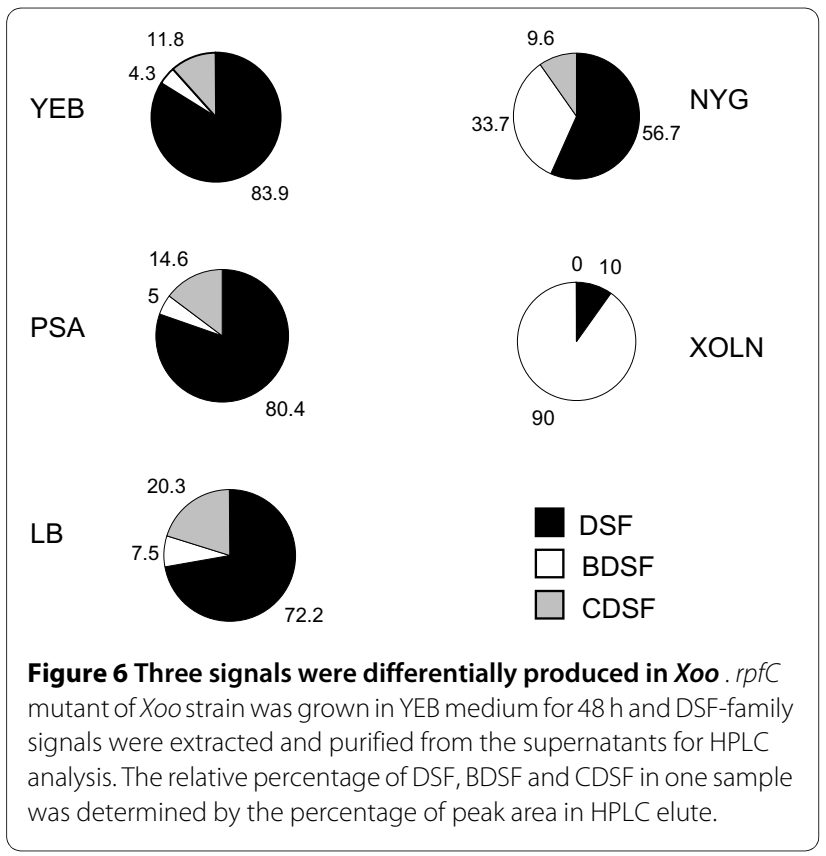

for DSF extraction and purification by adjusting the cell culture supernatant's $\mathrm{pH}$ from 7 to 4 prior to ethyl acetate extraction. The results showed that Xoo strain KACC10331 produces 3 DSF-family signals, including the previously characterized DSF in Xcc [5], BDSF in $B c c$ [9] and a novel DSF-family signal CDSF (Fig. 2). In contrast, only DSF was identified from the same volume of unacidified supernatants and its yield was about 10-fold lower than that from the acidified supernatants (data not shown). The findings encouraged us to check whether Xcc could also produce other DSF-family signals in addition to DSF. By using this modified protocol, we confirmed that $X c c$ also produced the same 3 signals as Xoo (data not shown). Taken together, these results suggest that both $X o o$ and Xcc produce multiple DSF-family signals, which is consistent with the previous finding that $S$. maltophilia strain WR-C produces a range of extracellular fatty acids, including DSF and seven structural derivatives [7]. It remains to be determined why and how bacteria produce multiple DSF-family signals. Although our results showed that DSF, BDSF and CDSF are all functional signals on the induction of EPS production and xylanase activity, we still could not rule out the possibility that these structurally distinct molecules might have different roles. Alternatively, these DSF-family signals might be functionally interchangeable and the mixture of them might simply be a mater of circumstance from a relatively promiscuous RpfF enzyme. The latter was further supported by the experimental findings that culture media influenced the production of DSF-family signals (Fig. 6). Xoo is a vascular pathogen, and the nutrients available in the xylem are probably different from those of the media used in this study. Thus, to determine what the true signal is used for in vivo quorum sensing during multiplication inside the vascular system of rice will be one of the key subjects of future work.

So far, little is known about the DSF biosynthesis pathway except that RpfF is the key enzyme involved in DSF biosynthesis. RpfF is predicted to be a putative enoylCoA hydratase, but the precursors of DSF-family signals and the mechanism of catalysis remain to be determined [29]. Given that CDSF differs from DSF in only one double bond, it is highly likely that they were not derived from one single precursor, whereas BDSF was produced from another precursor. The data from this study showed that RpfF is essential for production of DSF, BDSF and CDSF, suggesting that RpfF could accommodate and use at least two types of precursors for the synthesis of different DSF-family signals. The findings that the maximum production of BDSF occurred ahead from the other two signals suggest that these precursors are produced differentially during bacterial growth. The notion is agreeable with the observations that the medium composition affected the ratio of the 3 DSF-family signals (Fig. 6). 
The previous work on $X c c$ revealed that the unsaturated double bond at the $\alpha, \beta$ position of DSF is important for it signalling activity and the saturated derivative is about 20,000 times less active than DSF [5]. BDSF is structurally different from DSF in the methyl substitution at the C-11 position (Fig. 2C). Similarly, DSF and BDSF had comparable effects on EPS production and on extracellular xylanase activity in Xoo, but CDSF was less active than its two analogues (Fig. 3). Presumably, the extra double bond at the $\mathrm{C}_{5}-\mathrm{C}_{6}$ of CDSF may affect its configuration, which hinders its accessibility to across the outer membrane or interaction with the sensor kinase. Consistent with this notion, farnesoic acid (3,7,11-trimethyl-2,6,10-dodecatrienoate), which contains two more double bonds in addition to the $\alpha, \beta$ double bond, shows a lower biological activity than DSF in Xcc [5]. Taken together, our results suggest that the DSF signalling mechanisms, especially at the level of the signal production autoregulation, are likely highly conserved in Xcc and Xoo.

\section{Conclusions}

Xoo strain KACC10331 produces multiple DSF-family signals, including DSF, BDSF and CDSF, when grown in rich media. Xoo uses a similar mechanism as previously described in Xcc to autoregulate the biosynthesis of the DSF-family signals. All the three DSF-family molecules are active signals in induction of the virulence factor production in Xoo although the efficiency may vary. The amount and ratio of the DSF-family signals produced by Xoo are influenced by culture medium composition.

\section{Methods}

\section{Bacterial strains and growth conditions}

Xoo wild type strain KACC10331 and the derivates were described previously [25]. Xoo strains were routinely grown at $30^{\circ} \mathrm{C}$ in $\mathrm{YEB}$ medium with $10 \mu \mathrm{g} / \mathrm{ml}$ cephalexin unless otherwise stated, which comprises $5 \mathrm{~g} / \mathrm{L}$ yeast extract, $10 \mathrm{~g} / \mathrm{L}$ tryptone, $5 \mathrm{~g} / \mathrm{L}$ sodium chloride, $5 \mathrm{~g} / \mathrm{L}$ sucrose, $0.5 \mathrm{~g} / \mathrm{L} \mathrm{MgSO}_{4}$. The NYG medium comprises 5 $\mathrm{g} / \mathrm{L}$ peptone, $3 \mathrm{~g} / \mathrm{L}$ yeast extract and $20 \mathrm{~g} / \mathrm{L}$ glycerol. PSA medium contains $10 \mathrm{~g} / \mathrm{L}$ peptone, $10 \mathrm{~g} / \mathrm{L}$ sucrose, and 1.0 g/L Na-glutamate. The composition of XOLN medium: $\mathrm{K}_{2} \mathrm{HPO}_{4} 0.7 \mathrm{~g} / \mathrm{L}, \mathrm{KH}_{2} \mathrm{PO}_{4} 0.2 \mathrm{~g} / \mathrm{L},\left(\mathrm{NH}_{4}\right)_{2} \mathrm{SO}_{4} 1 \mathrm{~g} / \mathrm{L}$, $\mathrm{MgCl}_{2} 0.1 \mathrm{~g} / \mathrm{L}, \mathrm{FeSO}_{4} 0.01 \mathrm{~g} / \mathrm{L}, \mathrm{MnCl}_{2} 0.001 \mathrm{~g} / \mathrm{L}, 0.0625 \%$ tryptone, $0.0625 \%$ yeast extract, sucrose $2 \mathrm{~g} / \mathrm{L}$ [30]. All tryptone, peptone and yeast extract were from Becton, Dickinson and Company (USA).

\section{Bioassay and quantification analysis of DSF-like signals}

DSF bioassay and quantification was performed as described previously [5]. Briefly, Xoo strains were grown for 2 days until an $\mathrm{OD}_{600}$ of 2.3 and $25 \mu \mathrm{l}$ of cell cultures were added to each well. The bioassay plates were incu- bated at $28^{\circ} \mathrm{C}$ for $24 \mathrm{hr}$. DSF activity was indicated by the presence of a blue halo around the well. To quantify DSF production, blue halo zone widths in the bioassay were converted to DSF units using the formula: DSF(unit $\mathrm{ml}^{-1}$ ) $=0.134 \mathrm{e}^{(1.9919 \mathrm{~W})}$, where $\mathrm{W}$ is the width in centimeters of the blue halo zone surrounding each well. Relative level of DSF-family signals in one sample was quantified using peak area in HPLC elute. One unit of DSF was defined as $100,000 \mu \mathrm{V} / \mathrm{sec}$.

\section{Purification of DSF, BDSF and CDSF}

Xoo strain was cultured in YEB medium for 48 h. Five liters of bacterial supernatant were collected by centrifugation at 3,800 rpm for $30 \mathrm{~min}$ at $4^{\circ} \mathrm{C}(\mathrm{J} 6-\mathrm{HC}$ Centrifuge, BECKMAN COULTER ${ }^{\mathrm{m}}$ ). The $\mathrm{pH}$ of the supernatants was adjusted to 4.0 by adding hydrochloric acid prior to extraction with an equal volume of ethyl acetate twice. The ethyl acetate fractions were collected and the solvent was removed by rotary evaporation at $40^{\circ} \mathrm{C}$ to dryness. The residue was dissolved in $20 \mathrm{ml}$ of methanol. The crude extract, divided into four batches, was subjected to flash column chromatography using a silica gel column $(12 \times 150 \mathrm{~mm}$, Biotage Flash $12 \mathrm{M}$ cartridge), eluted with ethyl acetate-hexane $(25: 75, \mathrm{v} / \mathrm{v}, 0.05 \%$ acetic acid). The collected active component was then applied to HPLC on a C18 reverse-phase column $(4.6 \times 250 \mathrm{~mm}$, Phenomenex Luna), eluted with water in methanol $(20: 80, \mathrm{v} / \mathrm{v}, 0.1 \%$ formic acid) at a flow rate of $1 \mathrm{ml} / \mathrm{min}$ in a Waters 2695 system with 996 PDA detector.

\section{Structure analysis}

${ }^{1} \mathrm{H},{ }^{13} \mathrm{C},{ }^{1} \mathrm{H}-{ }^{1} \mathrm{H}$ COSY, and heteronuclear multiple quantum coherence (HMQC) nuclear magnetic resonance (NMR) spectra in $\mathrm{CDCl}_{3}$ solution were obtained using a Bruker DRX500 spectrometer operating at $500 \mathrm{MHz}$ for ${ }^{1} \mathrm{H}$ or $125 \mathrm{MHz}$ for ${ }^{13} \mathrm{C}$. High-resolution electrospray ionization mass spectrometry was performed on a Finnigan/ MAT MAT 95XL-T mass spectrometer.

\section{Quantitative determination of extracellular xylanase activity and EPS production}

The fresh colonies of Xoo strains were inoculated in $50 \mathrm{ml}$ of YEB liquid medium with or without DSF-family signals at a starting $\mathrm{OD}_{600}$ of 0.05 . After growth for two days, the bacterial cultures at an $\mathrm{OD}_{600}$ of 2.5 were collected and the supernatants were prepared by centrifugation at $14,000 \mathrm{rpm}$ for $10 \mathrm{~min}$. The extracellular xylanase activity in the culture supernatants of Xoo strains were measured by using 4-O-methyl-D-glucurono-D-xylan-Remazol Brilliant Blue R (RBB-Xylan; Sigma Co.) according to the methods described previously $[31,25]$. To determine the production of EPS, potassium chloride was added to 10 $\mathrm{ml}$ of the supernatants at a final concentration of $1.0 \%(\mathrm{w} /$ v). Two volumes of absolute ethanol were added to the 
supernatants and the mixtures were then kept at $-20^{\circ} \mathrm{C}$ for overnight. The precipitated EPS molecules were spun down and dried at $55^{\circ} \mathrm{C}$ oven overnight before determination of dry weight. Each experiment was repeated at least twice with triplicate. The data shown are the average of triplicate with standard deviation.

\section{Additional material}

\section{Additional file 1 MS analysis of DSF from Xoo strain KACC10331. High-} resolution electrospray ionization mass spectrometry was performed on a Finnigan/MAT MAT 95XL-T mass spectrometer.

Additional file 2 MS analysis of BDSF from Xoo strain KACC10331. Additional file 3 HPLC analysis of ethyl acetate extract from the supernatant of $r$ ffF mutant cell culture. The same volume of rpfF mutant supernatant was extracted for DSF-family signals using the same protocol as described in the Materials and Methods. (a) DSF, (b) BDSF, and (c) CDSF.

Additional file 4 Effects of different concentrations of DSF, BDSF and CDSF on EPS production and xylanase activity. (A) EPS production. (B) The xylanase activity in the supernatant of cell culture.

\section{Authors' contributions}

JEW carried out all the HPLC and NMR analysis. JSC generated all the mutants. The study was conceived, designed, and coordinated by LHZ and $\mathrm{YWH}$, who also drafted the manuscript and extracted all the DSF signals, and did the virulence factor production assay. All authors read and approved the final manuscript.

\section{Acknowledgements}

This research was supported by funding from the Agency for Science, Technology and Research (A*STAR), Singapore.

\section{Author Details}

'Institute of Molecular and Cell Biology, 61 Biopolis Drive, 138673, Singapore and 2 Department of Plant Medicine, Chungbuk National University, Cheongju 361-763, Korea

Received: 19 March 2010 Accepted: 9 July 2010

Published: 9 July 2010

\section{References}

1. Von Bodman SB, Bauer WD, Coplin DL: Quorum sensing in plantpathogenic bacteria. Annu Rev Phytopathol 2003, 41:455-482.

2. Zhang $\mathrm{LH}$, Dong $\mathrm{YH}$ : Quorum sensing and signal interference: diverse implications. Mol Microbiol 2004, 53:1563-571.

3. Bassler BL, Losick R: Bacterially Speaking. Cell 2006, 125:237-246.

4. Barber CE, Tang JL, Feng JX, Pan MQ, Wilson TJG, Slater H, Dow JM, Williams P, Daniels MJ: A novel regulatory system required for pathogenicity of Xanthomonas campestris is mediated by a small diffusible signal molecule. Mol Microbiol 1997, 24(3):556-566.

5. Wang LH, He YW, Gao YF, Wu JE, Dong YH, He C, Wang SX, Weng LX, Xu JL, Tay L, Fang RX, Zhang LH: A bacterial cell-cell communication signal with cross-kingdom structural analogues. Mol Microbiol 2004, 51:903-912

6. Colnaghi Simionato AV, da Silva DS, Lambais MR, Carrilho E: Characterization of a putative Xylella fastidiosa diffusible signal factor by HRGC-El-MS. J Mass Spectrom 2007, 42:490-496.

7. Huang TP, Wong AC: Extracellular fatty acids facilitate flagellaindependent translocation by Stenotrophomonas maltophilia. Res Microbiol 2007, 158:702-711.

8. Fouhy Y, Scanlon K, Schouest K, Spillane C, Crossman L, Avison MB, Ryan RP, Dow JM: Diffusible signal factordependent cell-cell signaling and virulence in the Nosocomial pathogen Stenotrophomonas maltophilia. J Bacterio/ 2007, 189:4964-4968.

9. Boon C, Deng Y, Wang LH, He YW, Xu JL, Fan Y, Pan SQ, Zhang LH: A novel DSF-like signal from Burkholderia cenocepacia interferes with Candida albicans morphological transition. ISME J 2008, 2:27-36.
10. He YW, Wang C, Zhou L, Song H, Dow JM, Zhang LH: Dual signaling functions of the hybrid sensor kinase RpfC of Xanthomonas campestris involve either phosphorelay or receiver domain-protein interaction. J Biol Chem 2006, 281:33414-33421.

11. Slater H, Alvarez-Morales A, Barber CE, Daniels MJ, Dow JM: A twocomponent system involving an HD-GYP domain protein links cell-cell signaling to pathogenicity gene expression in Xanthomonas campestris. Mol Microbiol 2000, 38:986-1003.

12. Ryan RP, Fouhy Y, Lucey JF, Crossman LC, Spiro S, He YW, Zhang LH, Heeb S, Cámara M, Williams P, Dow JM: Cell-cell signaling in Xanthomonas campestris involves an HD-GYP domain protein that functions in cyclic di-GMP turnover. Proc Natl Acad Sci USA 2006, 103:6712-6717.

13. Tao F, He YW, Wu DH, Swarup S, Zhang LH: The cyclic nucleotide monophosphate domain of Xanthomonas campestris global regulator Clp defines a new class of cyclic di-GMP effectors. J Bacterio/ 2010, 192(4):1020-1029.

14. He YW, Ng AY, Xu M, Lin K, Wang LH, Dong YH, Zhang LH: Xanthomonas campestris cell-cell communication involves a putative nucleotide receptor protein Clp and a hierarchical signalling network. $\mathrm{Mol}$ Microbiol 2007, 64:281-292.

15. Chatterjee S, Sonti RV: rpfF mutants of Xanthomonas oryzae pv. oryzae are deficient for virulence and growth under low iron conditions. Mol Plant-Microbe Interact 2002, 15:463-471.

16. Chatterjee S, Wistrom C, Lindow SE: A cell-cell signaling sensor is required for virulence and insect transmission of Xylella fastidiosa. Proc Natl Acad Sci USA 2008, 105:2670-2675

17. Huang TP, Wong AC: A cAMP receptor protein regulated cell-cell communication system mediates expression of a FecA homologue in Stenotrophomonas maltophilia. Appl Environ Microbiol 2007, 73:5034-5040

18. Shen $Y$, Ronald P: Molecular determinants of disease and resistance in interactions of Xanthomonas oryzae pv. oryzae and rice. Microbes Infect 2002, 4(13):1361-1367.

19. Ray SK, Rajeshwari R, Sonti RV: Mutants of Xanthomonas oryzae pv. oryzae deficient in general secretory pathway are virulence deficient and unable to secrete xylanase. Mol Plant-Microbe Interact 2000, 13:394-401

20. Köplin R, Arnold W, Hötte B, Simon R, Wang G, Pühler A: Genetics of xanthan production in Xanthomonas campestris: the xanA and xanB gene are involved in UDP-glucose and GDP-mannose biosynthesis. $J$ Bacteriol 1992, 174:191-199.

21. Hu J, Qian W, He C: The Xanthomonas oryzae pv. oryzae egIXoB endoglucanase gene is required for virulence to rice. FEMS Microbiol Lett 2007, 269:273-279.

22. Rajeshwari R, Jha G, Sonti RV: Role of an in planta expressed xylanase of Xanthomonas oryzae pv. oryzae in promoting virulence on rice. $\mathrm{Mol}$ Plant-Microbe Interact 2005, 18:830-837.

23. Jha G, Rajeshwari R, Sonti RV: Functional interplay between two Xanthomonas oryzae pv. oryzae secretion systems in modulating virulence on rice. Mol Plant-Microbe Interact 2007, 20:31-40.

24. Feng JX, Li QQ, Wen HX, Zhou DL, Ma QS, Daniels MJ: Cloning and characterization of the rpfC gene of Xanthomonas oryzae pv. oryzae: involvement in exopolysacchride production and virulence to rice. Mol Plant-Microbe Interact 1996, 9:664-666.

25. Jeong KS, Lee SE, Han JW, Yang SU, Lee BM, Noh TH, Cha JS: Virulence Reduction and Differing Regulation of Virulence Genes in rpf Mutants of Xanthomonas oryzae pv. oryzae. Plant Pathol J 2008, 24(2):143-151.

26. Lee BM, Park YJ, Park DS, Kang HW, Kim JG, Song ES, Park IC, Yoon UH, Hahn JH, Koo BS, Lee GB, Kim H, Park HS, Yoon KO, Kim JH, Jung CH, Koh $\mathrm{NH}$, Seo JS, Go SJ: The genome sequence of Xanthomonas oryzae pathovar oryzae KACC10331, the bacterial blight pathogen of rice. Nucleic Acids Res 2005, 33(2):577-586.

27. Ochiai H, Takeya M, Sasaki A, Kaku H: Genome sequence of Xanthomonas oryzae pv. oryzae suggests contribution of large numbers of effector genes and insertion sequences to its race diversity. Japan Agricultural Research Quarterly 2005, 39:275-287.

28. Salzberg SL, Sommer DD, Schatz MC, Phillippy AM, Rabinowicz PD, Tsuge S, Furutani A, Ochiai H, Delcher AL, Kelley D, Madupu R, Puiu D, Radune D, Shumway M, Trapnell C, Aparna G, Jha G, Pandey A, Patil PB, Ishihara H, Meyer DF, Szurek B, Verdier V, Koebnik R, Dow JM, Ryan RP, Hirata H, Tsuyumu S, Lee SW, Seo YS, Sriariyanum M, Ronald PC, Sonti RV, Van Sluys MA, Leach JE, White FF, Bogdanove AJ: Genome sequence and rapid 
evolution of the rice pathogen Xanthomonas oryzae pv. oryzae PXO99A. BMC Genomics 2008, 9:204-219.

29. He YW, Zhang LH: Quorum sensing and virulence regulation in Xanthomonas campestris. FEMS Microbiol Rev 2008, 32:842-857.

30. Fu JF, Tseng YH: Construction of lactose-utilizing Xanthomonas campestris and production of Xanthan gum from whey. Appl Environ Microbio/ 1990, 56(4):919-923.

31. Biely P, Mislovicova D, Toman R: Remazol Brilliant Blue-xylan: A soluble chromogenic substrate for xylanases. Methods Enzymol 1988, 160:536-542.

doi: $10.1186 / 1471-2180-10-187$

Cite this article as: He et al., Rice bacterial blight pathogen Xanthomonas oryzae pv. oryzae produces multiple DSF-family signals in regulation of virulence factor production BMC Microbiology 2010, 10:187

Submit your next manuscript to BioMed Central and take full advantage of:

- Convenient online submission

- Thorough peer review

- No space constraints or color figure charges

- Immediate publication on acceptance

- Inclusion in PubMed, CAS, Scopus and Google Scholar

- Research which is freely available for redistribution

Submit your manuscript at www.biomedcentral.com/submit
C) Biomed Central 